\title{
Factors Hindering Quality Performance in Construction Projects: An Empirical Study
}

\author{
Raw'a Hijazi \\ Faculty of Business, Al-Zaytoonah University of Jordan \\ Amman-Jordan \\ E-mail: Rawa_tash@yahoo.com
}

Received: March 10, 2021

Accepted: April 27, 2020

Published: April 27, 2021

doi:10.5296/jmr.v13i2.18520

URL: https://doi.org/10.5296/jmr.v13i2.18520

\begin{abstract}
Construction industry is crucial for the economy of any country. Learning from failure is important to reach effective quality performance in construction projects. This will, in turn, contribute to the development of the construction industry and the country as a whole. Although quality is an important criterion in the project management success, but it receives less attention than cost and time in project management literature. Moreover, critical success factors (CSFs) are identified more often than critical failure factors (CFFs) in construction literature. Hence, there is still a lack of attention on critical failure factors affecting quality performance in construction projects. Construction industry is full of uncertainties, especially in the current era of COVID-19 Pandemic. This adds to the necessity of studying critical failure factors in construction industry. This study aims to identify the critical factors that have adverse effect on quality performance in construction projects, address their relative importance, and suggest ways to attain good quality performance in construction projects. Based on literature review, an initial list of failure attributes of quality performance in construction projects was prepared. Then it was refined based on suggestions from experienced professionals in the construction industry in the Jordanian context. A questionnaire was distributed to experts in the construction industry. The responses were analyzed using Statistical Package for the Social Sciences (SPSS). The analyses used here are factor analysis and tests of its appropriateness. Using these analyses, the most critical factors that impede quality performance in construction were identified and ranked. The study revealed that the most influencing failure factors are the managerial factor, the culture and environment factor, and the contractor factor.
\end{abstract}

Keywords: Failure Factors, quality performance, construction projects, factor analysis 


\section{Introduction}

2021, Vol. 13, No. 2

\subsection{The Study Problem}

The construction industry is complex and associated with uncertainty (Mahamid, 2020). There are many causes of uncertainty in construction projects, such as the performance of construction parties, resources availability, and contractual relations (Abd El-Karim et al., 2017). The uniqueness of construction projects, the highly competitive environment, and the challenges facing the construction industry give rise to many problems, such as delays, conflict, and deficiency of a quality assessment system (Bitamba and An, 2020). The quality of construction projects affects the development of construction industry (Vadivel et al., 2016). Global, estimates indicate that construction sector consumes approximately $40 \%$ of the total energy and $40 \%$ of all raw materials. Besides, it produces approximately $40 \%$ of waste (Atwa, 2017).

In general, project management success is measured according to cost, time, and quality. The three criteria have been known as "iron triangle" (Larsen et al., 2016). Besides, scholars recognize it as "triple constraint" (Anoop et al., 2016). Moreover, in the golden triangle people are placed at the center of the iron triangle; because people help maintain a balance among cost, time and quality (Abiodun et al., 2017).

Scholars have defined quality differently. A quality pioneer W. Edwards Deming's pointed out that quality has to be defined from the stakeholder's perspective. Correspondingly, "Quality involves meeting or exceeding customer expectations" (Goetsch and Davis, 2016, p.3). Quality in construction refers to customer's satisfaction within a specified budget (Modi et al., 2017). A comprehensive definition of quality in construction projects is provided by American Society of Civil Engineers [ASCE] (2012) as follows: "Quality is determined by the degree to which the project participants fulfill their responsibilities to each other" (p5). People or organizations involved in all or some of the different stages of the project are called project stakeholders. Primary stakeholders include top management, project manager, client, designer, and general contractor (Lester, 2017, pp. 37, 38). This is Consistent with the total quality setting in which customers exist inside and outside the organization. In more details, any employee whose work follows that of another employee is an internal customer. while, an external customer interacts with the company after producing the product (Goetsch and Davis, 2016, p.91). Simply stated, Quality in construction can be defined as project stakeholders' satisfaction.

A number of scholars affirmed the importance of quality in projects. Time and cost are the primary areas of focus in project management, while quality is a secondary one (Jha and Iyer, 2006). Construction projects and quality cannot exist without each other (Modi et al., 2017). Focusing on quality will result in guiding the project management toward strategic viewpoint (Ganesh, 2016; Jugdev and Müller, 2005). It is essential to guarantee quality due to the high cost of buildings (Davidkumar and Kathirvel, 2015). Quality is one of the vital factors in any construction project. Besides, poor quality leads to problems in cost, time and safety (Modi et al. ,2017), which in turn influence the construction industry and the country economy (Abd El-Karim et al., 2017). 
To improve the effectiveness of construction projects, CSFs and CFFs have been studied by a great number of scholars. For a project to be successful, it is necessary to understand the CSFs right from the beginning (Ranawat, et al., 2018). Rockart was the first to use the term 'CSF' in the context of project management in 1982 and defined it as "those factors predicting success on projects" (Sanvido et al., 1992 in Chan et al., 2004). The CSFs were developed from CFFs which were defined as "the deficiency or lack of various critical factors" (Pinto and Mantel, 1990). In summary, CFFs are key issues that adversely affect achieving the objectives of a project. Learning from failure is important for all engineering works (El-sokhn and Othman, 2014; Pol and Konnur, 2017). Moreover, Kisavi and Ngugi (2019) pointed to the crucial importance of project performance which is achieved through avoiding the project's failure. In the United States of America (USA), a number of educational resources have been developed for nearly a decade to make it easier for engineering students and practicing engineers to learn from failures (Delatte ,2010). The focus in this study is on quality objective. The extracted CFFs in this study are key issues that cause poor quality performance in a construction project.

Managers avoid discussing failure circumstances for different reasons. So, knowledge about failures in construction is not well organized (Ortega, 2000). Although a number of Scholars have studied Critical factors of construction industry in different developing countries, but there is still a lack of empirical evidence on these factors within the developing countries. Besides, the results are limited to the countries in which such studies have been conducted (Toor and Ogunlana, 2008). There is a lack of studies on CFFs affecting quality performance of construction projects in the Jordanian context. To cover this gap, the current study attempts to identify and evaluate such factors in the Jordanian context.

\subsection{Importance of the Study Problem}

The main problem of this study is the deficiency of studies on CFFs affecting quality performance of construction projects in the Jordanian context. The study is important for people in construction organizations where interest is in project management success. The study importance stems from the following: firstly, this study will cover a gap in literature on studies of CFFs in one of the developing countries. Secondly, the importance of the realm of study; construction industry is pivotal for the economy of any country. Thirdly, the study will enrich the understanding about CFFs that influence quality in construction projects. Finally, the study will add to the cumulative science through providing scholars with important insights for further researches. Towards covering the gap mentioned above, the study aims to attain the following objectives: evaluating the CFFs by introducing a framework for factors hindering quality performance in construction projects in the Jordanian context and addressing the relative importance of the CFFs, providing project managers and other construction stakeholders with useful recommendations, in consideration of the study results, to reach a good quality performance in construction projects, and providing scholars with fruitful insights for future studies 


\section{3 literature Review}

There exists a considerable body of literature on critical factors in projects. Scholars have studied critical factors in projects in diverse manners. A number of scholars have prepared a list of critical factors without grouping them (Othman and Mydin, 2014 ). On the other hand, other scholars have aggregated critical factors in groups (Babalola and Ojo, 2016). Moreover, some scholars have ranked the critical factors by degree of importance (Babu, 2015). Others have not studied the relative importance of critical factors (Othman and Mydin, 2014). The focus in some studies has been on CSFs (Pol and Konnur, 2017), while others have focused on CFFs (Santoso and Gallage, 2019). Besides, few studies have recognized both types, i.e., CSFs and CFFs (Jha and Iyer, 2006). Concerning the measures, some studies have covered the three main performance measures, i.e., time, cost and quality (Oke et al., 2016). Others have covered two measures, such as: quality and cost (Zehro and Jkhsi, 2020), cost and time (Abd El-Karim et al., 2017) or one performance measure, for example: cost (Iyer and Jha, 2006), quality (Jha and Iyer, 2006). Some scholars have recognized critical factors in construction industry theoretically from literature (Chan et al., 2004). On the other side, critical factors are identified empirically using questionnaires (Davidkumar and Kathirvel, 2015). Some studies investigated critical factors in Construction projects in general (Santoso and Gallage, 2019). Other body of literature studied critical factors in Joint venture construction projects (Mba and Agumba, 2018), or Home building construction (Zehro and Jkhsi, 2020), or road construction projects (Kisavi and Ngugi, 2019).

Scholars have identified lists of critical factors affecting quality performance in construction projects. For instance, Singh and Sharma (2020) drew attention to the significant areas in which critical factors are usually identified such as employees and skills, functions, methods, and technologies. A study by Irfan et al. (2019) on a random sample from different developing countries revealed a negative relationship between stakeholder conflicts and quality in construction projects. Dorcas et al. (2019) found construction mistakes, use of unskillful labors, destitute checking and inspection, destitute motivation system, destitute management commitment and leadership styles, deficiency of good quality construction materials, restriction of finance, and weak timely supervision as the most significant factors that influence projects' quality in Nigeria. Santoso and Gallage (2019) identified top 10 critical factors affecting the performance of large construction projects in Sri Lanka, namely large project scope, site management by the contractor, complication of the project, poor planning and scheduling of activities, weakness of experience of the contractor, schedule suspensions, unstable government policies regarding the project, imprecise cost estimates, construction errors and quality issues of completed work, and imprecise time estimates. Sheikh et al. (2019) findings indicated that the significant factors that influence the process quality of building projects in Pakistan during the construction phase are the selection of a suitable contractor, the presence of feedback system and quality of shop sketches received from subcontractors. A study conducted by Kusi et al., (2018) in the Nepalese context indicated that the main two failure factors were the lack of knowledge and commitment of the contractor on construction quality and overall quality culture and working environment. In the Indian 
context, Ganesh (2016) classified main causes of reduced quality in building projects into four groups, namely capable labor absenteeism, material deficiency, rework, and meager supervision. Project design cost, project complication, deficiency of resources, quality of equipment and raw materials in Nigerian construction industry were pointed out by Oke et al. (2016) as factors of poor quality performance of consultants. The results of Shanmugapriya and Subramanian (2015) indicated that leadership and process related problems are the most distinctive factors of quality performance in construction projects in India. El-sokhn and Othman (2014) identified twenty-one project failure factors from literature review and classified them according to project stage, project player, and the failure factors source. Othmanand and Mydin (2014) pointed out that the main failure factors in housing projects are inadequate communication, poor information, insufficient controls, shortage of technical skills, and deficient feedback leading to repetitive errors. a study in India by Jha and Iyer (2006) revealed that conflict among project participants, adverse socio-economic environment, disturbing climatic condition, PM's obliviousness and lack of knowledge, imprecise project conceptualization, and offensive competition during tendering are the CFFs affecting quality performance of projects. An earlier study by Atkinson (1999) indicated that most defects in construction projects are due to human.

\section{Methodology}

Based on extensive review of various literatures on factors of poor quality performance in construction projects in different developing countries, an initial list of 31 failure attributes was prepared. Since the selected attributes were from studies in contexts other than Jordan, the initial list was introduced to 7 professionals in the construction industry in Jordan in order to refine it. The refinement process was performed through interviewing the professionals face to face. All of the professionals were engineers with 20 or more years of experience in construction management. Four of the professionals were from consultancy organizations, while the other three were from contracting organizations. They were interviewed individually and required to evaluate each failure attribute as being relevant or irrelevant to the Jordanian context. Also, they were required to provide suggestions. The suggestions were taken into consideration and the irrelevant attributes were removed from the list. In result, a final list of 25 failure attributes was developed. A questionnaire-based survey approach was used. The questionnaire consisted of cover page and two sections: The first section, which covered background information of the respondents, included question to profile their qualification, experience in the construction industry, and organization type. The second section established the critical failure attributes; at the beginning poor quality performance indications were clarified in a paragraph; poor quality performance can be indicated by the following: the project doesn't comply with the culture of the organization, quality problems in accomplished works, technical problems are not fixed successfully, change orders concerning technical requirements, complaints from the client concerning the quality of accomplished works, and complaints from the contractor concerning the ambiguous and exaggerated technical requirements (Low and Ong, 2014). After the clarifying paragraph, the respondents were required to indicate their level of agreement with the criticality of failure attributes to poor quality performance in the projects. A five-point Likert scale was used, with 5=strongly agree, 4=agree, 3=neutral, 
$2=$ disagree, and $1=$ strongly disagree. Targeted respondents were experts in the construction industry holding at least a bachelor's degree and having at least a 5-year experience in the construction industry. 506 questionnaires were distributed through email and direct distribution in different construction organizations (consultancy or contracting organizations) in Jordan. 171 questionnaires were returned resulting in a response rate of approximately (34\%). All of the returned questionnaires were judged valid. The responses were analyzed using SPSS software. Factor analysis was conducted to reduce the list of failure attributes to a meaningful smaller number of factors and to address the relative importance of them.

\section{Results and Discussion}

\subsection{Descriptive Analysis and Tests of Appropriateness}

The majority of the respondents (71.2\%) had graduated with a bachelor's degree. $20.3 \%$ of the respondents had graduated with a master's degree, while $8.5 \%$ of the respondents had graduated with a $\mathrm{PhD}$ degree. 93 participants $(54.4 \%)$ had worked in construction industry for a period of 15 years or more and 32 participants (18.7\%) had worked in construction industry for a period of 10 to 14 years, while 46 participants $(26.9 \%)$ had worked in construction industry for a period of 5 to 9 years. 93(54.4\%) participants were from consultancy organizations, whereas 78 participants $(45.6 \%)$ were from contracting organizations.

Before performing Exploratory Factor Analysis (EFA), it is necessary to conduct tests of appropriateness of factor analysis for factor extraction. Kaiser-Meyer-Olkin Measure of Sampling Adequacy (KMO) and Bartlett's Test of Sphericity were conducted. KMO value is 0.802 , which is considered as meritorious indicating that the distribution of data is adequate for conducting factor analysis. Besides, the significant value for Bartlett's Test of Sphericity is 0.000 , which is less than the significant level 0.05 , so it indicates that the data are approximately multivariate normal and acceptable for factor analysis.

\subsection{Failure Factors Extracted by Factor Analysis}

Factor analysis was conducted on 25 attributes to attain a smaller number of expressive factors and to rank them based on their relative importance. The extraction method used was Principal Component Analysis (PCA). Varimax with Kaiser Normalization was the rotation method used. Factor loadings $( \pm 0.5)$ or greater were taken into consideration since they are significant (Hair et al, 2010:135). Five failure factors were extracted. Names were assigned to the factors according to the attributes contained within them. The extracted failure factors, variance explained by each of them, cumulative variance explained and rank are shown in Table 1. 
Table 1. Total Variance Explained and Rank 2021, Vol. 13, No. 2

\begin{tabular}{|c|c|c|}
\hline $\begin{array}{l}\text { Failure Factor Number } \\
\text { (Name) }\end{array}$ & Variance explained & Rank \\
\hline $\begin{array}{l}\text { Failure Factor } \\
\text { ( Managerial) }\end{array}$ & $18.92 \%$ & 1 \\
\hline $\begin{array}{l}\text { Failure Factor } 2 \text { (Culture and } \\
\text { Environment) }\end{array}$ & $13.76 \%$ & 2 \\
\hline Failure Factor 3 (Contractor) & $12.56 \%$ & 3 \\
\hline $\begin{array}{l}\text { Failure Factor } 4 \text { (Labor and } \\
\text { Technology) }\end{array}$ & $10.88 \%$ & 4 \\
\hline \multirow[t]{2}{*}{ Failure Factor 5 ( Client) } & $10.61 \%$ & 5 \\
\hline & $\begin{array}{l}\text { Cumulative } \quad \text { Variance } \\
\text { Explained }= \\
66.73 \%\end{array}$ & \\
\hline
\end{tabular}

Extraction Method: Principal Component Analysis

It can be seen from Table 1. that the variances explained by the five failure factors are $18.92 \%, 13.76 \%, 12.56 \%, 10.88 \%$, and $10.61 \%$ respectively.

Variance explained by each factor is an indication of its relative importance (Zikmund et al., 2008:596). Thus, the five factors are ranked in a descending order as follows: managerial, culture and environment, contractor, labor and technology, and client. In total, the five factors explain $66.73 \%$ of the variance. This is equivalent to R square in multiple regression analysis (Zikmund et al., 2008:596) and indicates that the researcher has $66.73 \%$ of the information in the 5 factors that are in the original 25 attributes.

The extracted failure factors, the attributes included in each of them, and their loadings are presented in Table 2. 
Table 2. Failure Factors Structure

\begin{tabular}{|c|c|}
\hline Failure Factor Description & Loading \\
\hline Failure Factor 1 ( Managerial) & \\
\hline Conflicts between project manager (PM) and top management & 0.829 \\
\hline $\begin{array}{l}\text { Conflicts between PM and other outside stakeholders such as } \\
\text { sub-contractor and owner }\end{array}$ & 0.765 \\
\hline Suspending important decisions & 0.738 \\
\hline Unawareness of proper planning tools and techniques by PM & 0.728 \\
\hline Poor monitoring and feedback tools & 0.637 \\
\hline Negative attitude of PM and project participants & 0.601 \\
\hline Disorganized resources allocation & 0.594 \\
\hline Failure Factor 2 (Culture and Environment ) & \\
\hline $\begin{array}{l}\text { Overlooking the project quality objectives in order to achieve } \\
\text { schedule and cost }\end{array}$ & 0.721 \\
\hline Conflicts among team members & 0.668 \\
\hline Tendency to pass on the blame to others & 0.664 \\
\hline Unfavorable political and economic environment & 0.576 \\
\hline Unfavorable social environment & 0.563 \\
\hline $\begin{array}{l}\text { There is no adequate consideration of the quality issues during } \\
\text { contractor's selection }\end{array}$ & 0.558 \\
\hline $\begin{array}{l}\text { Too many constraint codes discourage contractor in } \\
\text { implementing quality }\end{array}$ & 0.547 \\
\hline Failure Factor -3 (Contractor) & \\
\hline Lack of awareness of contractor about benefits of implementing & 0.729 \\
\hline
\end{tabular}




\begin{tabular}{|l|l|}
\hline quality management tools in construction. & \\
\hline $\begin{array}{l}\text { Inadequacy of understanding of contractor about construction } \\
\text { quality }\end{array}$ & 0.707 \\
\hline $\begin{array}{l}\text { Scantiness of understanding of contractor that cost of poor } \\
\text { quality is much higher than that of operating process. }\end{array}$ & 0.639 \\
\hline Destructive competition among contractors at tender stage & 0.630 \\
\hline Failure Factor $\mathbf{4}$ (labor and Technology) & 0.898 \\
\hline Insufficient investment in advanced technology & 0.752 \\
\hline Shortage of adequate training & 0.634 \\
\hline Scarcity of skilled labor & 0.581 \\
\hline Extreme rotation of the labor in construction organizations & 0.730 \\
\hline Failure Factor 5 (Client) & 0.727 \\
\hline Insisting on speedy processes by client while issuing tender & \\
\hline Mismatch in capabilities of client and designer & 0.727 \\
\hline Dearth of client commitment to quality & 0.79 \\
\hline
\end{tabular}

Rotation Method: Varimax with Kaiser Normalization

The failure factors extracted in this study along with the most distinguishing attributes Comprised in them are described below.

Failure Factor 1 (Managerial)

The attributes of failure factor 1 in Table 2. are mainly related either to PM or to top management. Thus, it is labelled a managerial factor. Attributes included in this factor are ranked in a descending order according to loading. Loading indicates strength of relationship between each attribute and the failure factor (Zikmund et al., 2008,594). So, conflicts between PM and top management, conflicts between PM and other outside stakeholders, and suspending important decisions are the top three attributes in factor 1 . If PM and top management work in a team spirit and positive attitude, the desired quality is achieved. Similarly, effective communication can resolve conflicts in a satisfactory way. Moreover, the management should give priority to crucial decisions, allocate resources professionally, apply appropriate planning and monitoring tools, embed risk management 
and change management in construction plans in order to be ready for any challenges such as the current one (COVID-19 Pandemic). Besides, PM should follow a transformational leadership style. Transformational leadership style delivers a strong feeling of community to project team, enables creative thinking, and improves performance (Maqbool et al., 2017; Tabassi et al., 2017).

Failure Factor 2 (Culture and Environment)

Attributes under failure factor 2 are linked to quality culture and external environment. So, it is named as culture and environment. Quality objectives should be given the same importance as schedule and cost objectives. Besides, it is essential for people in projects to put conflict aside. Moreover, a culture of being responsible should be disseminated instead of passing blame to others. Top management should help in this affair by ensuring agreed-upon accountabilities. External environment is full of risks and challenges, especially during this era of COVID-19 Pandemic. In order to be able to cope with the dynamic political, economic, and social environment, flexible plans should be prepared at an early stage of project life cycle with risk management embedded in them. Also, it is important to consider quality issues during contractor's selection, and to reduce constraint codes to encourage contractors to implement quality. It is useful in this context to provide rewards for contractors for exceeding the goals.

Failure Factor 3 (Contractor)

Contractor is assigned as a name for failure factor 3 since attributes within it revolve around the contractors. If contractors lack awareness and understanding about the importance of construction quality and the consequences of neglecting quality in construction, it hinders quality. In addition, destructive competition at tender stage affects quality adversely. The selection of a low bidder usually leads to poor quality performance in projects. Quality performance in construction projects is enhanced if contractors increase their awareness about construction quality, about the costs of poor quality, and about the welfares of implementing quality management tools in construction. Benchmarking is very useful in this context; if contractors develop benchmarking system, it will develop their performance in light of best practices in the construction industry. More to the point, contractors should train labor to adhere to quality and select the competent sub-contractors and labor to perform the works in the project. Moreover, if destructive competition is replaced with a positive one, it is well for all parties and for quality performance in construction.

Failure Factor 4 (labor and Technology)

Attributes in failure factor 4 describe labor and construction technology. This factor includes insufficient investment in advanced technology, shortage of adequate training, scarcity of skilled labor, and extreme rotation of the labor in construction organizations. If construction organizations invest in advanced technology, provide suitable training for labor, and reduce rotation of them, it has progressive effect on quality performance of construction projects. Top management should shift to investing in cost-efficient technologies that utilize renewable resources. PM should integrate sustainability into 
project planning process \& process improvement. Sustainability not only contributes to the quality of projects, but also enhance the quality of human life (Atwa, 2017).

\section{Failure Factor 5 (Client)}

It can be observed from Table 2. that insisting on speedy processes by client while issuing tender, mismatch in capabilities of client and designer, and dearth of client commitment to quality fall under the last factor. They are associated with the clients. That is why a name (Client) is assigned to this factor. It is obvious that client may hamper quality performance in construction projects. Client should allow for a suitable time to attain high quality performance. Besides, client should be more committed to quality. Moreover, the designer should be able to understand the client's needs and interests as well as being able to convert them into a communicative and satisfying design. Early engagement of client in communication is effective in avoiding confusions.

The findings of this study are relevant to the ones concluded in literature. For instance, Jha and Iyer (2006) study results revealed that conflict among project participants;adverse socio-economic environment, PM's obliviousness, negative attitude of PM and project participants, holding crucial decisions in abeyance, and offensive competition during tendering are among the major factors that adversely affect project quality performance.

Besides, four out of the five extracted factors in the current study overlap with the ones observed by (Kusi et al., 2018) as factors leading to poor quality performance in construction firms. Kusi et al. (2018) ranked four factors in a descending order according to importance as follows: the awareness and commitment of the contractors in construction quality, overall quality culture and the working environment, assistance from client and workforce, and construction technology and working system. However, the rank of these factors in the current study is different. Moreover, the results of the current study reveal a fifth new factor, which is the managerial one.

Recalling that in the golden triangle people are central due to their vital role in maintaining a balance among cost, time and quality (Abiodun et al., 2017), the human element in this study loads significantly in the five extracted factors as presented in Table 2. This also coincides with the findings of Atkinson (1999). Moreover, it can be observed in Table 2. that conflict attributes have very high loadings; conflicts between PM and top management has a loading of 0.829. Further, the loading of conflicts between PM and other outside stakeholders such as sub-contractor and owner is 0.765 . While, 0.668 is the loading of conflicts among team members. This result is in line with the findings of Irfan et al. (2019) study which revealed that stakeholder conflicts in construction projects affect quality adversely. At this point, a vital issue stems which is the necessity of studying the root causes of conflicts in construction projects.

\section{Conclusions}

The aims of this study were to establish a framework for factors hindering quality performance in construction projects in the Jordanian context, address the relative importance of the extracted CFFs, provide project managers and other construction 
stakeholders with useful recommendations, in consideration of the study results, to reach a good quality performance in construction projects, and to provide scholars with fruitful insights for future studies.

In this study 25 attributes for reduced quality in construction projects were aggregated in five failure factors by means of factor analysis. Total variance explained by the 5 CFFs was $66.73 \%$.

Regarding the relative importance of the extracted factors, results revealed that the most influencing factors are the managerial factor, followed by the culture and environment factor, and then the contractor factor. The labor and technology factor and the client factor are less significant than others. In light of the relative importance results, it is concluded that quality performance in projects isn't just all about equipment or materials, but it is also about project stakeholders and their attitudes along with competencies, which are the main success factors behind good quality performance.

Quality performance is important to the success of construction projects. In this study some of the previous conclusions from literature were re-established. The crucial factors influencing quality of construction projects basically revolved around the human resource. Human role was significant in all factors including the fourth factor, which was technology and labor. Among the 25 attributes that constituted the five factors, "conflicts between PM and top management" was found to be the most distinctive attribute within the managerial factor. Whereas, "overlooking the project quality objectives in order to achieve schedule and cost" was established as number one under the culture and environment factor. Besides, "lack of awareness of contractor about benefits of implementing quality management tools in construction" was the major attribute in the contractor factor. While, "insufficient investment in advanced technology" was the most recognized attribute within the labor and technology factor. Finally, "insisting on speedy processes by client while issuing tender" was the most significant client-related attribute.

This study adds to the literature on CFFs in projects. It provides new empirical evidence of the CFFs that affect quality performance in construction projects from construction experts' perspective in the context of Jordan. It can be replicated in other contexts. Assembling attributes into factors will help top management, project managers, and other stakeholders of construction projects avoid numerous problems by focusing on preventing CFFs in future projects. Grouping failure attributes into factors provides a brief list of CFFs. Focusing on a short list instead of an extended one will be easier. Addressing the relative importance of CFFs will help the top management and the project manager giving priority to the most critical factors.

\section{Recommendations}

Based on conclusions drawn in this study, all stakeholders in the construction industry in the Jordanian context are recommended to be aware of and concentrate on avoiding failure factors that impede quality performance in construction projects. By doing so, quality performance in construction projects can be improved and consequently the construction industry can be developed. This study provides recommendations for all project 
stakeholders as follows: Main recommendations for top management include making top management support a priority in the project, providing rewards for contractors for exceeding the goals, training employees to adhere to quality, emphasizing employee empowerment, building a friendly environment in construction organizations, selecting competent PM, awarding bids to competent contractors, ensuring agreed-upon accountabilities, assuring client involvement at an early stage to be able to manage the interface between client expectations and what is feasible, imparting innovative culture in construction organizations, developing the knowledge, skills, and responsibility awareness of different stakeholders in the project, investing in cost-efficient technologies that utilize renewable resources and being well-prepared in construction plans for any risks or changes to be able to survive in times of crisis like the current one (COVID-19 Pandemic). Focal recommendations for PM are following a transformational leadership style, assuring effective project planning and control in which risk management and change management are rooted, focusing on project stakeholders' expectations, building a friendly project environment, training the project team to adhere to quality, conducting effective processes for selecting team members, distributing work responsibilities clearly in order to reduce conflict, guaranteeing mutual trust, fostering effective communication, coordination, knowledge sharing, and continuous learning. Contractors are recommended to develop benchmarking system, train labor to adhere to quality, and select the competent sub-contractors and labor to perform the works in the project. Furthermore, contractors are recommended to focus on positive competition which is beneficial for all parties as well as quality performance in construction. Regarding the clients, they are recommended to allow for a suitable time to attain high quality performance, be more committed to quality, and to engage in communications at early stages to avoid confusions. Moreover, the designers are recommended to develop their ability to understand the client's needs and interests as well as to convert needs into a communicative and satisfying design.

\section{Future Scope}

This study was conducted on construction projects in general. Future research could identify CFFs in a specific type of construction projects such as joint venture projects. Moreover, further research could be conducted to identify CFFs of construction projects and classify them based on the different stages of project life cycle. Additionally, CFFs in different contexts could be identified in further research. What is more, root causes of the failure attributes, such as conflict and lack of awareness about quality in construction could be studied in detail in further research.

\section{Acknowledgments}

I would like to express my gratitude to professionals in the construction industry in Jordan who assisted in refining the list of attributes. Thanks are due to all experts in different consultancy and contracting organizations in Jordan who provided the data necessary to accomplish this study.

\section{References}

Abd El-Karim, M., El Nawawy, O., \& Abdel-Alim, A. (2017). Identification and 
assessment of risk factors affecting construction projects. HBRC Journal, 13(2), 202-216. https://doi.org/10.1016/j.hbrcj.2015.05.001

Abiodun, O. E., Segbenu, N. S. , \& Oluseye, O. (2017). Factors affecting contractors' performance in construction project delivery in Akure, Ondo State, Nigeria. Journal of Knowledge Management. Economics and Information Technology, 7(4), 1- 23.

American Society of Civil Engineers [ASCE] (2012). ASCE manuals and reports on engineering practice.no. 73. Quality in The Constructed Project: A Guide for owners, designers and constructors (3rd ed.). ASCE.

Anoop, T., Asadi, S. S., Prasad, AVS., (2016). The Critical Success Factors affecting the performance of construction industry. International Journal of Civil Engineering and Technology (IJCIET), 7(6), 669-675.

Atkinson A.R. (1999). The role of human error in construction defects. Structural Survey. 17(4), 231-236. https://doi.org/10.1108/02630809910303006

Atwa, M. S. (2017). Quality Assurance in Construction as a Sustainability Approach .PM World Journal, 6(2),1-14.

Babalola, H. I., \& Ojo, O. J. (2016). An Investigation into factors affecting the performance of public construction projects in Ondo State, Southwestern. Nigeria. Civil and Environmental Research, 8(1), 72-79.

Babu, N. J. (2015). Factors affecting success of construction project. IOSR Journal of Mechanical and Civil Engineering, Ver. V, 12(2), 2320-2334.

Bitamba, B.F.\& An, S.H. (2020). Study on factors affecting the performance of construction projects in the Democratic Republic of the Congo. South African Journal of Industrial Engineering, 31(1), 12-25. https://doi.org/10.7166/30-4-2193

Chan A. P. C., Scott D., Chan A. P. L. (2004). Factors affecting the success of a construction project. Journal of Construction Engineering and Management, ASCE, 130(1), 153-155. https://doi.org/10.1061/(ASCE)0733-9364(2004)130:1(153)

Davidkumar, C. \& Kathirvel, P. (2015). A study on factors influencing quality of construction Projects. International Journal for Research in Applied Science \& Engineering Technology, 3(5), 200-207.

Delatte, N. (2010). Failure literacy in structural engineering. Engineering structures Journal, 32(7), 1952-1954. https://doi.org/10.1016/j.engstruct.2009.12.015

Dorcas, O. A. B., Elkanah, A. O., and John, O. O. (2019). Most critical factors responsible for poor project quality performance in building construction industry (A case study of three major cities in Nigeria). European International Journal of Science and Technology, $8(2), 1-14$.

El-sokhn, N. H. \& Othman, A. A. E. (2014, May 27-29). Project failure factors and their impacts on the construction industry: a literature review [Paper presentation]. ICCAE-10 
2014: 10th International Conference on Civil and Architecture Engineering. Military Technical Kollege Kobry El-Kobbah, Cairo, Egypt. https://doi.org/10.21608/iccae.2014.44191

Ganesh S. M., (2016). Poor quality in Building projects. International Journal of Engineering Science \& Research Technology, 5(7), 1147-1153.

Goetsh, D. L. \& Davis, S. B. (2016). Quality Management for Organizational Excellence: Introduction to Total Quality (8th ed.). Pearson.

Hair, J. F., Black, W. C., Babin, B. J., \& Anderson R. E. (2010). Multivariate data analysis (7th ed.). Pearson Prentice Hall.

Irfan, M., Thaheem, M.J., Gabriel, H.F., Malik, M.S.A. \& Nasir, A.R. (2019). Effect of stakeholder's conflicts on project constraints: a tale of the construction industry. International Journal of Conflict Management, 30(4), 538-565. https://doi.org/10.1108/IJCMA-04-2019-0074

Iyer, K. C., \& Jha, K. N. (2006). Critical factors affecting schedule performance: Evidence from Indian construction projects. Journal of Construction Engineering and Management, 132(8), 871-881. https://doi.org/10.1061/(ASCE)0733-9364(2006)132:8(871)

Jha K. N. \& Iyer K. C. (2006) Critical Factors Affecting Quality Performance in Construction Projects. Total Quality Management, 17(9), 1155-1170. https://doi.org/10.1080/14783360600750444

Jugdev, K. \& Müller, R. (2005). A retrospective look at our evolving understanding of project success. Project Management Journal, 36(4), 19-31. https://doi.org/10.1177/875697280503600403

KISAVI, J. M. \& NGUGI, L. (2019). Critical factors and their influence on performance of road construction projects in Kiambu County, Kenya. International Journal of Scientific and Education Research, 3(3), 44-66.

Kusi, M., Zhao, F. A, \& Sukamani, D. (2018). Study of performance level of Nepalese construction firms in construction quality. North American Academic Research, 1(5), 137-153.

Larsen, J., Shen, G., Lindhard, S. \& Brunoe, T. (2016) Factors affecting schedule delay, cost overrun, and quality level in public construction projects. Journal of Management in Engineering, 32(1), 1-29. https://doi.org/10.1061/(ASCE)ME.1943-5479.0000391

Lester, A. (2017). Project Management, Planning and Control: Managing Engineering, Construction and Manufacturing Projects to PMI, APM and BSI Standards (7th ed.). Elsevier.

Low, S. P. \& Ong, J. (2014). Project Quality Management: Critical Success Factors for Buildings. Springer. https://doi.org/10.1007/978-981-287-074-2_4

Maqbool, R., Sudong, Y., Manzoor, N., \& Rashid, Y. (2017). The impact of emotional 
intelligence, project managers' competencies, and transformational leadership on project success: An empirical perspective. Project Management Journal, 48(3), 58-75. https://doi.org/10.1177/875697281704800304

Mahamid, I. (2020). Study of relationship between rework and labor productivity in building construction projects. Revista de la Construcción. Journal of Construction, 19(1), 30-40. https://doi.org/10.7764/rdlc.19.1.30-41

Mba, M. F. B., \& Agumba, J. N. (2018). Critical success factors influencing performance outcome of joint venture construction projects in South Africa: Comparison of first and second order models. Construction Economics and Building, 18(3), 74-94. https://doi.org/10.5130/AJCEB.v18i3.5885

Modi, H. J., Pathak, V. B., \& Yadav, N. B. (2017). Analysis top crucial factors of contract clauses and quality in construction projects using RII method. International Journal of Emerging Technologies and Innovative Research, 4(5), 239-243.

Oke, A., Ogungbile, A., Oyewobi, L., \& Tengan, C. (2016). Economic development as a function of construction project performance. Journal of Construction Project Management and Innovation, 6(2), 1447-1459.

Ortega, I. (2000). Systematic prevention of construction failures. Institut Für Technologie Management (ITEM), 1-13, 9.

Othman, N. A. \& Mydin, M. A. O. (2014). Poor workmanship in construction of low cost housing. Analele Universitatii 'Eftimie Murgu', 21(1), 300-306.

Pinto, J. K., \& Mantel, S. J. (1990). The causes of project failure. IEEE Transactions on Engineering Management, 37(4), 269-276. https://doi.org/10.1109/17.62322

Pol, P. A. \& Konnur, B. A. (2017) Evaluation of success factors in construction industry by using RII. International Journal of Novel Research and Development, 2(4), 30-34.

Ranawat, H. S., Bhadoriya, G., \& Trivedi, M. (2018). Critical factors which are affecting the success of construction project in Gwalior division, India. International Journal of Applied Engineering Research, 13(11), 10108-10114.

Santoso, D. S. \& Gallage, P. G. M. P. (2019). Critical factors affecting the performance of large construction projects in developing countries: A case study of Sri Lanka. Journal of Engineering, Design and Technology, 18(3), 531-556. https://doi.org/10.1108/JEDT-05-2019-0130

Shanmugapriya, S. \& Subramanian, K. (2015). Structural equation model to investigate the factors influencing quality performance in Indian construction projects. Sadhana, 40(6), 1975-1987. https://doi.org/10.1007/s12046-015-0421-3

Sheikh, A. H. A. , Ikram, M. , Ahmad, R. M. , Qadeer, H. \& Nawaz, M. (2019). Evaluation of key factors influencing process quality during construction projects in Pakistan. Grey Systems: Theory and Application, 9(3), 321-335. https://doi.org/10.1108/GS-01-2019-0002 
Singh, M. \& Sharma, S. K. (2020). Critical Success Factors in Construction Projects. International Journal of Recent Technology and Engineering (IJRTE), 8(5). https://doi.org/10.35940/ijrte.E6408.018520

Tabassi, A. A., Roufechaei, K. M., Bakar, A. H. A., \& Yusof, N. A. (2017). Linking team condition and team performance: A transformational leadership approach. Project Management Journal, 48(2), 22-38. https://doi.org/10.1177/875697281704800203

Toor, S. and Ogunlana, S. O. (2008). Critical COMs of success in large-scale construction projects: Evidence from Thailand construction industry. International Journal of Project Management, 26, 420-430. https://doi.org/10.1016/j.ijproman.2007.08.003

Vadivel, T. S., Doddurani, M., Shobana, K. S., \& Kalidhass, B. (2016). Analyzing the factors affecting quality in construction. International Journal of Engineering Research \& Technology (IJERT) NCCETCE, 4(33),1-6.

Zehro, K., \& Jkhsi, S. (2020). Management, quality and economy in home building construction. International Journal of Advanced Engineering, Sciences and Applications, l(2), 12-17. https://doi.org/10.47346/ijaesa.v1i2.20

Zikmund, W. G., Babin, B. J., Carr, J. C., \& Griffin, M. (2008). Business Research Methods (8th ed.). Mason.

\section{Copyrights}

Copyright for this article is retained by the author(s), with first publication rights granted to the journal.

This is an open-access article distributed under the terms and conditions of the Creative Commons Attribution license (http://creativecommons.org/licenses/by/4.0/) 